\title{
Vulnerable parenting among mothers with substance abuse in their family of origin: a cross-sectional comparative study of mothers in an infant and toddler program
}

\author{
Eva Tedgård ${ }^{1,3,4^{*}}$ (1) and Maria Råstam ${ }^{1,2}$
}

\begin{abstract}
Objective: To investigate whether women raised in a family with substance abuse constitute a particularly vulnerable group of patients in an infant psychiatry setting and to identify the risk factors of suspected parental malfunctioning in women referred to treatment in an infant and toddler intervention program.

Background: A history of family substance abuse can severely disrupt the caretaking abilities of parents in ways that can have far-reaching consequences, and children growing up with insufficient parental care may incorporate this deficiency into their own parental behavior.

Methods: In total, 126 mothers completed self-report questionnaires assessing their substance abuse and health problems as well as problems in their family of origin. The index group was defined as women who reported substance abuse in their family of origin $(n=35)$. The comparison group was defined as women who denied substance abuse in their family of origin $(n=91)$.

Results: Symptoms of depression and anxiety were overrepresented in the total group of mothers compared with the Swedish norm. The index group had experienced parental divorce and traumatic life events more often and reported earlier substance abuse of their own. They had significantly more depression and ADHD symptoms and were more often single parents. All these factors can have a negative influence, separately or in combination, on the ability to practice sensitive parenting.
\end{abstract}

Conclusions: Female offspring of substance-abusing parents are an especially vulnerable group of patients. To prevent the intergenerational transmission of alcohol and drug abuse, it is important to identify parents with specific needs and to administer targeted treatment and support at primary health care centers and child psychiatric clinics.

Keywords: Parenting, Family of origin, Substance abuse, ADHD, Depression

\section{Background}

Many factors can have a negative influence on an individual's parenting abilities. For example, it is well documented that relationships in one's family of origin are an important factor affecting parenting skills (Solomon and George 2011). Parents who view their own early caregivers as hostile and insensitive are thought to be more likely

\footnotetext{
*Correspondence: eva.tedgard@med.lu.se

${ }^{4}$ Beritta Gurrisgatan 17, 21774 Malmö, Sweden

Full list of author information is available at the end of the article
}

to provide a more insecure environment for their own children (Liotti 2004; Solomon and George 1999, 2011). Substance abuse in the family of origin is another factor that can negatively affect parenting behavior (Howe 2005; Locke and Newcomb 2004). Parenting capability can also be influenced by a parent's experiences of an earlier traumatic life event (Cohen et al. 2008), health problems such as depression (Murray et al. 2011; Reck et al. 2008; Tronick and Reck 2009), anxiety (O'Connor et al. 2005), and attention deficit hyperactivity disorder (ADHD) 
(Chronis-Tuscano et al. 2008; Johnston et al. 2012), and substance abuse (Kroll 2004; Suchman et al. 2008).

The influence of parents' substance abuse on the health of their offspring is far-reaching (Anda et al. 2002; Bakoyiannis et al. 2014; Balsa et al. 2009; Elkins et al. 2004; Velleman et al. 2008) and can severely disrupt parents' caretaking abilities. Parental substance use disorder has been associated with increased aggression and vulnerability to stress in the affected offspring (Elkins et al. 2004; Dube et al. 2001). Studies have found associations between substance abuse in parents and the development of anxiety and affective disorder in their children (Chen and Weitzman 2005; Foley et al. 2004; Hill et al. 2008; Kelley et al. 2011); researchers have also found that children of parents who abuse substances are at an increased risk of experiencing substance abuse themselves (Buu et al. 2009; Kendler et al. 2015; Yule et al. 2013). Female offspring of women with alcoholism appear to have a greater risk of adult psychopathologies than male children (Morgan et al. 2010; Pearson et al. 2012). Children of parents with alcohol and/or drug abuse are also at risk of developing ADHD (Knopik et al. 2006), particularly children in families with multiple cases of alcohol abuse (Hill et al. 2008). Numerous studies have demonstrated a considerable overlap between ADHD and substance use disorder (Lee et al. 2011) (Iacono et al. 2008; Young et al. 2009). ADHD has also been found to be a significant predictor of substance abuse (Capusan et al. 2016; Wilens et al. 2011), and at least one in four individuals with substance abuse have ADHD (Ohlmeier et al. 2008; Sullivan and Rudnik-Levin 2001). It has been suggested that the dual diagnosis of substance abuse and ADHD carries an added risk of negative parenting (Johnston et al. 2012).

In the past decade, infant and toddler programs have been developed in child and adolescent psychiatry to help families with parenting problems promote child health and wellbeing and to support sensitive parenting. The most common problems in this setting are regulatory disorders in the child and mental health problems of the mother.

The aim of these intervention programs is to improve the parent-child relationship, increase parental responsiveness and reflectivity and parent-child emotional regulation and establish a secure attachment between the child and his or her parent/s. The intervention has a combination of interaction treatment were the parents are encouraged to become attentive to the child's emotions and initiatives of contact and psychotherapy for the parent (Neander and Engstrom 2009). The parents who participate in such programs have all exhibited impaired parenting behavior, but as a group, they are heterogeneous. An earlier report from an infant and toddler program in Sweden has found that approximately half of the mothers who joined the program with their infants had been raised with substance-abusing parents. Furthermore, these women, compared with other parents reported more symptoms in their children, more severe problems between them and their children and greater difficulty including the father in the treatment (Tedgård 2008). It is important to identify parents with pronounced needs to provide targeted treatment.

The objective of the present study was to investigate whether women raised in a family with substance abuse constitute a particularly vulnerable group of patients in an infant psychiatry setting and to identify risk factors for suspected parental malfunctioning in women referred to the intervention program for parent-child relationship problems. We compared women with and without substance abuse in their family of origin regarding psychosocial background factors, such as traumatic life events, parental separation, and family history of physical and mental health. We further explored participants' symptoms of depression, anxiety, ADHD, and substance abuse. Individuals with ADHD experience problems parenting (Knopik et al. 2006), but the frequency of ADHD among individuals seeking treatment for parenting problems has not been investigated to date.

We hypothesized that a woman's experience of substance abuse in her family of origin would be associated with more symptoms of anxiety, depression and higher risk of own substance abuse, thus putting her at a special risk for malfunctioning parenting.

Second, we hypothesized that there would be an increased prevalence of ADHD in our total sample of individuals with parenting problems and an even greater increased occurrence of symptoms indicative of ADHD in the subsample of individuals who had been raised in a family with substance abuse.

\section{Methods}

The current study focused on self-reported data from women participating with their children (aged 0-4 years) in a parent-child intervention program in a specialized outpatient infant and toddler psychiatric clinic in Malmö, Sweden, because of deficient parenting behavior and dysfunctional patterns of interaction with their child. All participants were referred for treatment because of parental problems either through self-referral $(60 \%)$ or through referral from a doctor or nurse from a primary care or pediatric clinic. Parents diagnosed with intellectual disabilities were not treated at the unit. The data were collected before the start of the intervention. The data are stored in a database titled "Factors important for parenting" (PUL), with the Skane Region County Council. 


\section{Subjects}

During the study period from May 1, 2011, to May 1, 2013, a total of 172 families were admitted to the clinic (Fig. 1).

The exclusion criteria were severe mental illness (psychosis or severe depression with hospitalization; $n=9$ ) or deficient knowledge of the Swedish language $(n=9)$, and 153 families were eligible. Nine families declined participation, and a further 19 failed to complete the questionnaires.

In the present study, only data from the mothers were included because the number of participating fathers was too small to conduct statistical analyses. Altogether, 126 mothers participated in the study with their children. In two families, both parents were women, and one in each pair was randomly selected to participate (Fig. 1).

In the next step, the total sample was divided according to substance abuse in the family of origin. The index group was defined as women who reported alcohol and/ or drug abuse in their family of origin, and the comparison group (COMP) was defined as women who denied alcohol and/or drug abuse in their family of origin.

\section{Instruments}

A self-reported questionnaire comprising 13 questions was specifically designed by the research group for the present study; it included questions pertaining to sociodemographic and psychosocial risk factors, such as traumatic life events, and somatic and psychiatric disorders, including substance abuse by the subjects and in the family of origin. The questionnaire included dichotomous questions, and the participants were asked to provide a more detailed answer to any initial positive responses (e.g., 'did you or any family member in your family of origin suffer from substance abuse problems? (Alcohol, prescribed drugs, illegal drugs) If yes, what kind?') (Table 1).

The Hospital Anxiety and Depression Scale (HADS) have been shown to be valid and reliable in medical

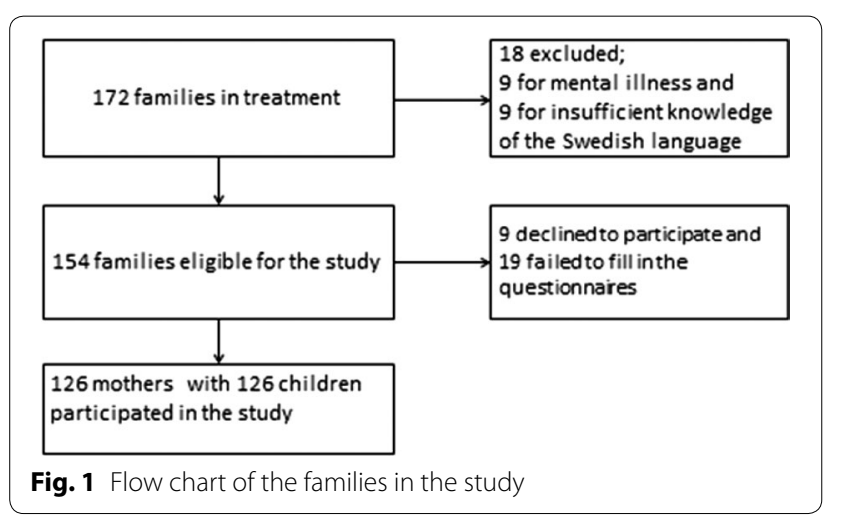

practice and research (Snaith 2003; Zigmond and Snaith 1983). The HADS is a Likert-style questionnaire consisting of 14 items (seven for anxiety and seven for depression). The score ranges from 0 (no anxiety) to 3 (greatest anxiety) for each question (Zigmond and Snaith 1983). The ranges of scores used to define cases are as follows: $0-7$, normal; $8-10$, mild disorder; $11-14$, moderate disorder and 15-21, and severe disorder (Bowling 2005; McDowell 2006; Snaith 2003). A cutoff score of 8 was used in the present study (Bjelland et al. 2002). The results were compared with the Swedish norm (Lisspers et al. 1997). Previous studies have supported the two-factor model used in this study (Helvik et al. 2011; Norton et al. 2013).

The Alcohol Use Disorders Identification Test (AUDIT) is an internationally well-validated questionnaire assessing alcohol use (Saunders et al. 1993). Alcohol consumption was measured by using the Swedish version of the AUDIT. The instrument consists of ten questions, each of which is scored from 0 to 4 points; the maximum score is thus 40. It contains questions pertaining to the level and frequency of alcohol consumption and heavy drinking, drinking behavior, and alcohol-related problems. Harmful use of alcohol is indicated by a score of $6-13$ points for women and 8-15 points for men, and alcohol dependence is indicated by a score $\geq 18$ points. The recommended cutoff scores, $\geq 6$ for women and $\geq 8$ for men, were used in this study (Berman et al. 2012).

The Drug Use Disorders Identification Test (DUDIT) is a thoroughly validated questionnaire evaluating the use of illegal drugs (Berman et al. 2005). Patients at risk from drug use was determined by using the Swedish version of the DUDIT. The instrument consists of eleven items designed to assess the consumption patterns of illicit drugs and problems related to drug use. The first nine items are scored on a five-point scale ranging from 0 to 4 , and the last two are scored on a three-point scale with the values 0,2 and 4 . Thus, the total scores range from 0 to 44, with higher scores suggesting a more severe drug problem. The DUDIT cutoff score for any type of problematic use (i.e., harmful use, substance abuse, or dependence) is generally recommended to be six for men and two for women. The following risk levels are suggested for the DUDIT scores: no drug-related problems (total scores 0-5/1), possible drug-related problems, i.e., risky or harmful drug habits that might be diagnosed as substance abuse/harmful use or dependence (6/2-24), and probable heavy dependence on drugs (scores $\geq 25$ ).

The ASRS v. 1.1 Adult ASRS Full Edition (WHO Adult $A D H D$ Self-Report Scale) is the WHO's self-report rating scale for adult ADHD (Kessler et al. 2005). The scale consists of 18 items that are consistent with the DSM-IV diagnostic criteria for ADHD symptoms. Items 1-9 (Part 
Table 1 Self-report questionnaire

\section{Self-report questionnaire}

1. Gender $\square$ female

2. Age

3. I grew up in

$\square$ male

$\square$ a small city
$\square$ the country side
In which country:

4. Were any of the following relatives born outside of Sweden

$\begin{array}{ll}\square \text { Mother } & \text { If yes, in which country: } \\ \square \text { Father } & \text { If yes, in which country: }\end{array}$

$\square$ Maternal grandparents If yes, in which country:

$\square$ Paternal grandparents If yes, in which country:

5. I have completed studies in the following

$\begin{array}{lll}\text { Elementary school } & \square \text { yes } & \square \text { no } \\ \text { Grammar school } & \square \text { yes } & \square \text { no } \\ \text { University/ College } & \square \text { yes } & \square \text { no }\end{array}$

6. My profession is

7. I am $\square$ married / cohabiting

$\square$ single

$\square$ widow / widower

8. Number of children in the family:

$$
\text { Sex and age }
$$

9. I lived with both parents

$\begin{array}{lrr}\text { Throughout childhood } & \square \text { yes } & \square \text { no } \\ \text { Until they separated } & \square \text { yes } \quad \square \text { no } \\ \text { My parents separated when I was } & & \text { years old }\end{array}$

I lived with people other than my parents,

who/when

10. I have experienced a severe / intimidating / traumatic life event $\square$ no $\quad \square$ yes, which type of trauma

11. Do/Did you or any member of your family of origin suffer from serious physical illness?

$\square$ no

$$
\begin{aligned}
& \square \text { yes - myself } \\
& \square \text { yes - my mother } \\
& \square \text { yes - my father } \\
& \square \text { yes - my siblings }
\end{aligned}
$$

Type of disease

12. Do/Did you or any member of your family of origin suffer from severe mental illness?

$$
\begin{aligned}
\square \text { no } & \square \text { yes }- \text { myself } \\
& \square \text { yes }- \text { my mother } \\
& \square \text { yes }- \text { my father } \\
& \square \text { yes }- \text { my siblings }
\end{aligned}
$$

Type of disease

13. Do/Did you or any member of your family of origin suffer from substance abuse problems (alcohol, prescribed drugs, illegal drugs?)

$\square$ no

Type of substance abuse

$$
\begin{aligned}
& \square \text { yes - myself } \\
& \square \text { yes - my mother } \\
& \square \text { yes }- \text { my father } \\
& \square \text { yes }- \text { my siblings }
\end{aligned}
$$


A) reflect symptoms of inattention, and items 10-18 (Part B) reflect symptoms of hyperactivity or impulsivity. The internal consistency of the ASRS in this dataset on the basis of Cronbach's alpha was .86 for Part A and .86 for Part B. ADHD symptoms were assessed by using the Swedish version of the 18-item ASRS. A higher cut-off level of $\geq 24$ was used in this study. All instruments have been validated for the Swedish population.

The Swedish Parenthood Stress Questionnaire (SPSQ) (Ostberg et al. 1997) is based on the Parent Domain of the Parenting Stress Index (Abidin 1995). The SPSQ measures parental stress and comprises 34 items divided into five subscales: incompetence, role restriction, social isolation, spouse relationship problems, and health problems. Together, these five subscales form an overall parenting stress score. The response options range from 'strongly agree' to 'strongly disagree,' which are scored on a Likert-type scale from 1 to 5 . Higher scores indicate more stress. The instrument has been used in several studies and has shown good psychometric properties.

The measures were administered by a well-experienced administrator who had participated in other studies and had a personal contact with each family. At admission, the parents were asked by the administrator to participate in the study. The administrator was then responsible for the distribution and collection of all the instruments.

\section{Statistical analysis}

The data analysis was performed using IBM SPSS 22.0 software for Windows. Descriptive statistics with means, medians and standard deviations were used to describe the findings. In the analysis of the findings, two-sample $t$ tests and Pearson's Chi square test for non-parametric data were used to identify significant differences between the index group and the comparison group. Statistical reasoning was performed on the basis of the statistical tests, with a significance level of 05 .

\section{Ethics}

Written informed consent was obtained from all participants. The study was approved by the Regional Ethics Committee at Lund University, Sweden.

\section{Results}

\section{Sociodemographic data}

In $66 \%$ of the 126 families, the mother had a Swedish background, and there were no differences between groups. The participants were between 19 and 46 years of age (mean age 32 years; SD 5.32), and there were no significant differences in age between the index and the COMP group. Sixty-seven percent of the mothers were primiparous, and there were no differences between groups. The 126 children (52 girls and 74 boys) were between 2 and 48 months old; $61 \%$ were younger than 12 months, and $84 \%$ of all mothers were married or cohabitating. Being a single mother was more common in the index group ( 29 vs. $11 \%, p=.048$ ). There were no differences in the level of education or employment status (Table 2).

\section{Substance abuse in parents in the family of origin}

Of the participating women, 35 (27\%) reported that they were raised in families with substance abuse. This group constituted our index group. In this group, 10 women reported that both of their parents abused substances during their childhood, 15 reported that only their father abused substances, and 10 reported that only their mother abused substances. Alcohol abuse was the most common form of abuse. The COMP group consisted of 91 women who denied alcohol and/or drug abuse in their family of origin.

\section{Mental/physical illness and divorce in the family of origin} There were no significant differences in the reported mental (41 vs. $38 \%, p=.835$ ) or physical health ( 29 vs. $35 \%, p=.570$ ) of the family of origin between groups. Divorce in the family of origin (66 vs. $38 \%, p=.005$ ) and having a sibling with substance abuse (29 vs. $4 \%$, $p=.0001$ ) were significantly more common in the index group (Table 3).

Table 2 Sociodemographic and psychosocial characteristics of the sample $(n=126)$

\begin{tabular}{|c|c|c|c|}
\hline & $\begin{array}{l}\text { Index women } \\
\mathrm{n}=35\end{array}$ & $\begin{array}{l}\text { COMP women } \\
\mathrm{n}=91\end{array}$ & $p$ value \\
\hline Age of mother (years) & 30.5 (SD 5.8) & $32.5(\mathrm{SD} 4.9)$ & $.075^{a}$ \\
\hline Primiparous & $23(66 \%)$ & $63(69 \%)$ & $.766^{b}$ \\
\hline Age of child (months) & 17.49 (SD 14.0) & 13.94 (SD 13.8) & $.189^{a}$ \\
\hline Married/cohabitating & $25(71 \%)$ & $81(89 \%)$ & $.048^{b}$ \\
\hline Educational background & & & $.225^{b}$ \\
\hline Elementary $<9$ years & $5(14 \%)$ & $5(6 \%)$ & \\
\hline $\begin{array}{l}\text { Grammar/secondary } \\
\text { 10-12 years }\end{array}$ & $14(40 \%)$ & $35(39 \%)$ & \\
\hline $\begin{array}{l}\text { College/university } \\
>12 \text { years }\end{array}$ & $16(46 \%)$ & $52(56 \%)$ & \\
\hline Unemployed & $6(17 \%)$ & $15(17 \%)$ & $.929^{b}$ \\
\hline Mother's ethnicity & & & $.038^{b}$ \\
\hline Swedish origin & $19(54 \%)$ & $64(70 \%)$ & \\
\hline Scandinavian origin & $5(14 \%)$ & $2(2 \%)$ & \\
\hline European origin & $6(17 \%)$ & $17(19 \%)$ & \\
\hline "Outside Europe" origin & $5(14 \%)$ & $8(9 \%)$ & \\
\hline
\end{tabular}

a $t$ test

b Pearson's Chi square 
Table 3 Physical and psychological illness and divorce in the family of origin

\begin{tabular}{llll}
\hline & $\begin{array}{l}\text { Index women } \\
\mathbf{n = 3 5}\end{array}$ & COMP women & $\mathbf{n}=\mathbf{9 1}$ \\
\hline Physical illness in the family of origin & $10(29 \%)$ & $32(35 \%)$ & .570 \\
Psychological illness in the family of origin (except for SUD) & $14(41 \%)$ & $35(38 \%)$ & .835 \\
Divorce in the family of origin & $23(66 \%)$ & $35(38 \%)$ & .005 \\
Sibling with substance abuse & $10(29 \%)$ & $4(4 \%)$ & .0001 \\
\hline
\end{tabular}

Pearson's Chi square

SUD substance use disorder

\section{Previous substance abuse in participants}

The women in the index group self-reported previous personal substance abuse significantly more often than women in the COMP group (20 vs. $1 \%, p=.0001$ ).

\section{Traumatic life events in participants}

The majority of the women reported traumatic life events (64\%). The most commonly reported events were severe physical abuse $(\mathrm{n}=30)$, sexual abuse $(\mathrm{n}=14)$, death in the immediate family $(\mathrm{n}=10)$, accidents $(\mathrm{n}=2)$, and having witnessed violence $(n=7)$. Traumatic life events were more common in the index group than in the COMP group ( 84 vs. $56 \%, p=.004$ ).

\section{Self-reported psychiatric symptoms at admission Anxiety symptoms according to the HADS}

Of the 126 women in the sample, 104 (82\%) had anxiety symptom scores that were above the cut-off $(\geq 8)$, and there were no significant differences between the index and COMP groups ( 83 vs. $82 \%, p=.225$; Table 4 ).

\section{Depression symptoms according to HADS}

Of the 126 women in the sample, $52(41 \%)$ reported depression symptom scores above the cut-off $(\geq 8)$. Symptoms of depression were more frequent in the index than in the COMP group (54 vs. $36 \%, p=.032$; Table 4 ).

\section{Substance abuse according to the AUDIT and DUDIT}

Of the 126 women in the sample, 21 (17\%) reported substance abuse (alcohol and/or drugs). According to the
AUDIT, there were no significant differences between groups $(14 \%$ in the index vs. $7 \%$ in the COMP group, $p=.171)$. According to the DUDIT, there were significantly more drug-related problems in the index group (18 vs. $6 \%, p=.033$; Table 4 ).

\section{Symptoms of hyperactivity and inattention according to the ASRS v. 1.1}

Of the 126 women in the sample, 24 (19\%) scored $\geq 24$ on either the inattentive or the hyperactive/impulsive symptom dimension, thus indicating 'highly probable ADHD'. The women in the index group scored $\geq 24$ significantly more often ( 31 vs. $14 \%, p=.019$; Table 4 ).

\section{Perceived parental stress according to the SPSQ}

Both groups of mothers reported significantly greater perceived parental stress than the SPSQ norm $(p=.0001)$ (Ostberg 1998). There were no significant differences between the index women (3.23; SD .50) and the COMP women (3.10; SD .61).

\section{Discussion}

The aim of this study was to investigate whether women raised in a family with substance abuse are a particularly vulnerable group of patients in an infant psychiatry setting and to identify the risk factors for suspected parental malfunctioning in women referred to treatment in an infant and toddler intervention program. Treatment in infant psychiatry has the overall goal of facilitating the development of the infant and optimizing the

Table 4 Self-report questionnaires, index women compared with COMP women

\begin{tabular}{lccc}
\hline & $\begin{array}{l}\text { Index women } \\
\mathbf{n = 3 5}\end{array}$ & $\begin{array}{l}\text { COMP women } \\
\mathbf{n = 9 1}\end{array}$ & $\boldsymbol{p}$ value \\
\hline HADS Symptoms of anxiety & $29(83 \%)$ & $75(82 \%)$ & .225 \\
HADS Symptoms of depression & $19(54 \%)$ & $33(36 \%)$ & .032 \\
AUDIT Harmful use of alcohol (past 12 months) & $5(14 \%)$ & $6(7 \%)$ & .171 \\
DUDIT Drug-related problems (past 12 months) & $6(18 \%)$ & $5(6 \%)$ & .033 \\
ASRS Highly probable ADHD & $11(31 \%)$ & $13(14 \%)$ & .019 \\
\hline
\end{tabular}

Pearson's Chi square 
relationship between the child and the parent to help foster a secure child-parent attachment. The development of the infant is in many ways dependent on the parent's ability to put his or her own needs aside and to focus on the child's signals. There are many possible different reasons for parents' inability to do this in an appropriate manner. A commonality among women attending treatment at an infant and toddler intervention program is experiencing stress, anxiety and uncertainty in their parenting (Neander and Engstrom 2009). Many of the women have psychiatric illnesses of their own and experienced complicated childhood conditions that may negatively influence their ability to meet the needs of their infants. During the planning of treatment, it is important to acknowledge the heterogeneity of these mothers, to try to identify relevant background factors and to develop targeted interventions for different groups of patients.

The sample in this study consisted of 126 mothers treated at an infant and toddler unit at a child and adolescent psychiatry clinic in Sweden. The index group of 35 mothers, representing almost a third of the families, reported substance abuse in their family of origin. They were compared with the other mothers, the COMP group $(\mathrm{n}=91)$. The findings suggested that women in the index group were affected more often by factors that could negatively influence their parenting. One of these factors was that more of these women had experienced their own parents' divorce, and they were more often single mothers. Divorce has a substantial impact on children's lives, including exposure to interparental conflict and changes in residences and standards of living, and it is a condition that leads to deleterious effects on children's healthrelated factors (Weitoft et al. 2003).

Another factor negatively affecting parenting ability was that women in the index group were exposed to different forms of traumatic life events more often. Previous research has suggested that traumatized parents are likely to be less emotionally or functionally available to their children and to have an authoritarian parenting style, including verbal hostility, physical coercion, and low nurturance. Maternal trauma may also be a predictor of the potential for parental abuse (Cohen et al. 2008; LyonsRuth et al. 2005; Schwerdtfeger et al. 2013).

A third factor was the higher prevalence of depressive symptoms among the index mothers. Post-partum depression is the most prevalent maternal psychiatric disorder; it occurs in 10-15\% of women and may lead to deficient and insensitive parenting (Reck et al. 2008). Extreme levels of maternal anxiety and depression during pregnancy and the postnatal period have been shown to negatively affect child development and parent-child relationships (Murray et al. 2011; O'Connor et al. 2005; Tronick and Reck 2009). There were no differences between groups in symptoms of anxiety or perceived parental stress. These problems were very frequent among all mothers, far above the Swedish norm, and may, at least partly, have led to their referral for treatment.

A fourth factor was the high proportion of previous substance abuse among the index mothers. One in five of the index women and only one woman in the COMP group reported previous substance abuse. However, these differences in substance abuse were not detected with the AUDIT self-report questionnaire, probably because the instrument assesses only the previous 12 months.

Finally, as hypothesized, symptoms indicative of ADHD were significantly more prevalent in the total sample of patients compared with the prevalence in the general population of adult women (Faraone and Biederman 2005), and ADHD symptoms were even more common in the index group with a family history of substance abuse. According to a recent review, parental ADHD symptoms may be associated with deficits in parenting control behavior, including family disorganization and chaos, less monitoring of child behavior, less effective problem solving in child-rearing, and more inconsistent and over-reactive disciplining (Johnston et al. 2012). Thus, significantly more women in the index group than in the COMP group scored above the cutoff level for 'highly probable ADHD' as a 'proxy' diagnosis of ADHD. This does not mean that these women had been diagnosed with ADHD. Many women with inattention problems remain undiagnosed until adulthood, when life exerts greater demands on their overall functioning (Quinn and Madhoo 2014). To the best of our knowledge, this is the first report of ADHD symptoms in women treated for parental dysfunction. This is important new knowledge that needs to be considered in the development of treatment models for these patients to account for their difficulties with impulsivity and executive functioning.

Hence, all these factors may separately or in combination have a negative influence on an individual's ability to practice sensitive parenting. It may also be difficult, in the context of treatment, to identify the specific needs of a person from a substance abusing family due to family dynamics, in which role confusion/parentification is common. Parentified children may perform parenting tasks and act very competent, but they are accustomed to neglecting their own needs (Macfie et al. 2015).

An obvious limitation of the present study is the use of a selected clinical population in which all participants had pronounced difficulties with parental functioning; hence, the findings cannot be applied to all grown children of parents with substance abuse.

Regarding the instruments, the sociodemographic and psychosocial data on the subjects and their family 
of origin reflect the subjective reports of the respondents. The most severe limitation is the lack of a validated self-report questionnaire for identifying our index group. There is a well-validated instrument, the Children of Alcoholics Screening Test (CAST) (Hodgins and Shimp 1995), that has been used in several larger population studies (Hill et al. 2008); however, because we wanted to use several other validated instruments, and the Regional Ethics Committee recommended a limited number of instruments, we decided to use our own self-report questionnaire instead of the CAST. The HADS has been criticized in the past for not sufficiently distinguishing between anxiety and depression, and it has been suggested that the HADS items should be considered in terms of general distress rather than anxiety and depression specifically (Norton et al. 2013). However, the results have been inconsistent; some studies have lent support to the two-factor model used in this study (Helvik et al. 2011; Norton et al. 2013). This study focused on the role of certain risk factors for insensitive parenting at the expense of others. Furthermore, the cross-sectional design does not allow for conclusions regarding causality.

\section{Conclusions}

In this study of mothers receiving treatment because of impaired parenting behavior, as indicated by their referral to a psychiatry clinic because of these difficulties, a substantial subgroup came from families with substance abuse. The findings suggest that even within a sample treated because of parenting malfunctions, women with substance abuse in their family of origin are a particularly vulnerable group of patients. The findings of a high reported prevalence of traumatic experiences and high levels of ADHD symptoms necessitate special treatment considerations. This knowledge should be important to health professionals, with the implication of screening for anxiety, depression and ADHD before the start of therapy. To prevent the intergenerational transmission of alcohol and drug abuse, it is important to identify parents with pronounced needs and to administer targeted treatment and support at primary health care centers and infant psychiatric clinics. Furthermore, this work suggests that it may be useful for prevention programs to identify at-risk women during pregnancy on the basis of a family history of substance abuse.

\footnotetext{
Abbreviations

ADHD: attention deficit hyperactivity disorder; ASRS: Adult ADHD Self-Report Scale; AUDIT: The Alcohol Use Disorder Identification Test; DUDIT: The Drug Use Disorder Identification Test; COMP: the comparison group; HADS: The Hospital Anxiety and Depression Scale; SPSQ: The Swedish Parenthood Stress Questionnaire; SUD: substance use disorder.
}

\section{Authors' contributions}

MR and ET were responsible for the study conception and contributed to the study design, instruments, analysis and interpretation of data. Both authors read and approved the final manuscript.

\section{Author details}

${ }^{1}$ Department of Clinical Sciences Lund, Child and Adolescent Psychiatry, Lund University, Baravägen 1, 22185 Lund, Sweden. ${ }^{2}$ Gillberg Neuropsychiatry Centre, Institute of Neuroscience and Physiology, University of Gothenburg, Göteborg, Sweden. ${ }^{3}$ Office for Healthcare 'Sund', Child and Adolescent Psychiatry, Infant and Toddler Unit, 20502 Malmö, Sweden. ${ }^{4}$ Beritta Gurrisgatan 17, 21774 Malmö, Sweden.

\section{Acknowledgements}

The authors gratefully acknowledge the families who participated in the study. The authors thank Pierre Carbonnier for the excellent statistical assistance, and Camilla Salomonsson for the administration of the questionnaires. This work was supported by Grants from the Skane Region County Council, the Lindhaga Foundation, and the Johan Olsson Foundation.

\section{Competing interests}

The authors declare that they have no competing interests.

\section{Ethics}

Written informed consent was obtained from all participants. The study was approved by the Regional Ethics Committee at Lund University, Sweden.

Received: 16 May 2016 Accepted: 11 August 2016

Published online: 13 September 2016

\section{References}

Abidin RR (1995) Parenting stress index [kit]. Psychological Assessment Resources, Odessa

Anda RF, Whitfield CL, Felitti VJ, Chapman D, Edwards VJ, Dube SR, Williamson DF (2002) Adverse childhood experiences, alcoholic parents, and later risks of alcoholism and depression. Psychiatr Serv 53(8):1001-1009. doi:10.1176/appi.ps.53.8.1001

Bakoyiannis I, Gkioka E, Pergialiotis V, Mastroleon I, Prodromidou A, Vlachos GD, Perrea D (2014) Fetal alcohol spectrum disorders and cognitive functions of young children. Rev Neurosci 25(5):631-639. doi:10.1515/ revneuro-2014-0029

Balsa Al, Homer JF, French MT (2009) The health effects of parental problem drinking on adult children. J Ment Health Policy Econ 12(2):55-66

Berman AH, Bergman H, Palmstierna T, Schlyter F (2005) Evaluation of the Drug Use Disorders Identification Test (DUDIT) in criminal justice and detoxification settings and in a Swedish population sample. Eur Addict Res 11(1):22-31. doi:10.1159/000081413

Berman AH, Wennberg P, Källmén H (2012) AUDIT \& DUDIT: identifiera problem med alkohol och droger. Gothia, Stockholm

Bjelland I, Dahl AA, Haug TT, Neckelmann D (2002) The validity of the Hospital Anxiety and Depression Scale: an updated literature review. J Psychosom Res 52(2):69-77. doi:10.1016/50022-3999(01)00296-3

Bowling A (2005) Measuring health: a review of quality of life measurement scales. Open University Press, Buckingham

Buu A, DiPiazza C, Wang J, Puttler LI, Fitzgerald HE, Zucker RA (2009) Parent, family, and neighborhood effects on the development of child substance use and other psychopathology from preschool to the start of adulthood. J Stud Alcohol Drugs 70(4):489-498

Capusan AJ, Bendtsen P, Marteinsdottir I, Larsson H (2016) Comorbidity of adult ADHD and its subtypes with substance use disorder in a large population-based epidemiological study. J Atten Disord. doi:10.1177/1087054715626511

Chen YY, Weitzman ER (2005) Depressive symptoms, DSM-IV alcohol abuse and their comorbidity among children of problem drinkers in a nationa survey: effects of parent and child gender and parent recovery status. J Stud Alcohol 66(1):66-73 
Chronis-Tuscano A, Raggi VL, Clarke TL, Rooney ME, Diaz Y, Pian J (2008) Associations between maternal attention-deficit/hyperactivity disorder symptoms and parenting. J Abnorm Child Psychol 36(8):1237-1250. doi:10.1007/s10802-008-9246-4

Cohen LR, Hien DA, Batchelder S (2008) The impact of cumulative maternal trauma and diagnosis on parenting behavior. Child Maltreat 13(1):27-38. doi:10.1177/1077559507310045

Dube SR, Anda RF, Felitti VJ, Croft JB, Edwards VJ, Giles WH (2001) Growing up with parental alcohol abuse: exposure to childhood abuse, neglect, and household dysfunction. Child Abuse Negl 25(12):1627-1640. doi:10.1016/ S0145-2134(01)00293-9

Elkins IJ, McGue M, Malone S, lacono WG (2004) The effect of parental alcohol and drug disorders on adolescent personality. Am J Psychiatry 161(4):670-676

Faraone SV, Biederman J (2005) What is the prevalence of adult ADHD? Results of a population screen of 966 adults. J Atten Disord 9(2):384-391. doi:10.1177/1087054705281478

Foley DL, Pickles A, Rutter M, Gardner CO, Maes HH, Silberg JL, Eaves LJ (2004) Risks for conduct disorder symptoms associated with parental alcoholism in stepfather families versus intact families from a community sample. J Child Psychol Psychiatry 45(4):687-696. doi:10.1111/j.1469-7610.2004.00263.x

Helvik A-S, Engedal K, Skancke RH, Selbæk G (2011) A psychometric evaluation of the Hospital Anxiety and Depression Scale for the medically hospitalized elderly. Nord J Psychiatry 65(5):338-344. doi:10.3109/08039488.201 1.560684

Hill SY, Shen S, Lowers L, Locke-Wellman J, Matthews AG, McDermott M (2008) Psychopathology in offspring from multiplex alcohol dependence families with and without parental alcohol dependence: a prospective study during childhood and adolescence. Psychiatry Res 160(2):155-166. doi:10.1016/j.psychres.2008.04.017

Hodgins DC, Shimp L (1995) Identifying adult children of alcoholics: methodological review and a comparison of the CAST- 6 with other methods. Addiction 90(2):255-267. doi:10.1111/j.1360-0443.1995.tb01043.x

Howe D (2005) Child abuse and neglect: attachment, development and intervention. Palgrave Macmillan, Basingstoke

lacono WG, Malone SM, McGue M (2008) Behavioral disinhibition and the development of early-onset addiction: common and specific influences. Annu Rev Clin Psychol 4:325-348. doi:10.1146/annurev. clinpsy.4.022007.141157

Johnston C, Mash EJ, Miller N, Ninowski JE (2012) Parenting in adults with attention-deficit/hyperactivity disorder (ADHD). Clin Psychol Rev 32(4):215-228. doi:10.1016/j.cpr.2012.01.007

Kelley ML, Pearson MR, Trinh S, Klostermann K, Krakowski K (2011) Maternal and paternal alcoholism and depressive mood in college students: parental relationships as mediators of ACOA-depressive mood link. Addict Behav 36(7):700-706. doi:10.1016/j.addbeh.2011.01.028

Kendler KS, Ohlsson H, Sundquist J, Sundquist K (2015) Triparental families: a new genetic-epidemiological design applied to drug abuse, alcoho use disorders, and criminal behavior in a Swedish national sample. Am J Psychiatry 172(6):553-560. doi:10.1176/appi.ajp.2014.14091127

Kessler RC, Adler L, Ames M, Demler O, Faraone S, Hiripi E et al (2005) The World Health Organization Adult ADHD Self-Report Scale (ASRS): a short screening scale for use in the general population. Psychol Med 35(2):245-256

Knopik VS, Heath AC, Jacob T, Slutske WS, Bucholz KK, Madden PAF et al (2006) Maternal alcohol use disorder and offspring ADHD: disentangling genetic and environmental effects using a children-of-twins design. Psychol Med 36(10):1461-1471. doi:10.1017/S0033291706007884

Kroll B (2004) Living with an elephant: growing up with parental substance misuse. Child Family Soc Work 9(2):129-140. doi:10.1111/j.1365-2206.2004.00325.x

Lee SS, Humphreys KL, Flory K, Liu R, Glass K (2011) Prospective association of childhood attention-deficit/hyperactivity disorder (ADHD) and substance use and abuse/dependence: a meta-analytic review. Clin Psychol Rev 31(3):328-341. doi:10.1016/j.cpr.2011.01.006

Liotti G (2004) Trauma, dissociation, and disorganized attachment: three strands of a single braid. Psychother Theory Res Pract Train 41(4):472-486. doi:10.1037/0033-3204.41.4.472
Lisspers J, Nygren A, Soderman E (1997) Hospital Anxiety and Depression Scale (HAD): some psychometric data for a Swedish sample. Acta Psychiatr Scand 96(4):281-286

Locke TF, Newcomb M (2004) Child maltreatment, parent alcohol and drugrelated problems, polydrug problems, and parenting practices: a test of gender differences and four theoretical perspectives. J Family Psychol 18(1):120-134

Lyons-Ruth K, Yellin C, Melnick S, Atwood G (2005) Expanding the concept of unresolved mental states: hostile/helpless states of mind on the Adult Attachment Interview are associated with disrupted motherinfant communication and infant disorganization. Dev Psychopathol $17(1): 1-23$

Macfie J, Brumariu LE, Lyons-Ruth K (2015) Parent-child role-confusion: a critical review of an emerging concept. Dev Rev 36:34-57. doi:10.1016/j. dr.2015.01.002

McDowell I (2006) Measuring health: a guide to rating scales and questionnaires. Oxford University Press, New York

Morgan PT, Desai RA, Potenza MN (2010) Gender-related influences of parental alcoholism on the prevalence of psychiatric illnesses: analysis of the National Epidemiologic Survey on Alcohol and Related Conditions. Alcohol Clin Exp Res 34(10):1759-1767. doi:10.1111/j.1530-0277.2010.01263.x

Murray L, Arteche A, Fearon P, Halligan S, Goodyer I, Cooper P (2011) Maternal postnatal depression and the development of depression in offspring up to 16 years of age. J Am Acad Child Adolesc Psychiatry 50(5):460-470. doi:10.1016/j.jaac.2011.02.001

Neander K, Engstrom I (2009) Parents'assessment of parent-child interaction interventions - a longitudinal study in 101 families. Child Adolesc Psychiatry Ment Health 3(1):8. doi:10.1186/1753-2000-3-8

Norton S, Cosco T, Doyle F, Done J, Sacker A (2013) The Hospital Anxiety and Depression Scale: a meta confirmatory factor analysis. J Psychosom Res 74(1):74-81. doi:10.1016/j.jpsychores.2012.10.010

O'Connor TG, Ben-Shlomo Y, Heron J, Golding J, Adams D, Glover V (2005) Prenatal anxiety predicts individual differences in cortisol in preadolescent children. Biol Psychiatry 58(3):211-217. doi:10.1016/j. biopsych.2005.03.032

Ohlmeier MD, Peters K, Te Wildt BT, Zedler M, Ziegenbein M, Wiese B et al (2008) Comorbidity of alcohol and substance dependence with attention-deficit/hyperactivity disorder (ADHD). Alcohol Alcohol 43(3):300-304. doi:10.1093/alcalc/agn014

Ostberg M (1998) Parental stress, psychosocial problems and responsiveness in help-seeking parents with small (2-45 months old) children. Acta Paediatr 87(1):69-76

Ostberg M, Hagekull B, Wettergren S (1997) A measure of parental stress in mothers with small children: dimensionality, stability and validity. Scand J Psychol 38(3):199-208

Pearson MR, D'Lima GM, Kelley ML (2012) Maternal and paternal alcohol misuse and alcohol-related outcomes among college students. Subst Use Misuse 47(6):708-717. doi:10.3109/10826084.2012.664237

Quinn PO, Madhoo M (2014) A review of attention-deficit/hyperactivity disorder in women and girls: uncovering this hidden diagnosis. Prim Care Companion CNS Disord. doi:10.4088/PCC.13r01596

Reck C, Struben K, Backenstrass M, Stefenelli U, Reinig K, Fuchs T et al (2008) Prevalence, onset and comorbidity of postpartum anxiety and depressive disorders. Acta Psychiatr Scand 118(6):459-468. doi:10.1111/j.1600-0447.2008.01264.x

Saunders JB, Aasland OG, Babor TF, de la Fuente JR, Grant M (1993) Development of the alcohol use disorders identification test (AUDIT): WHO Collaborative project on early detection of persons with harmful alcohol consumption-II. Addiction 88(6):791-804

Schwerdtfeger KL, Larzelere RE, Werner D, Peters C, Oliver M (2013) Intergenerational transmission of trauma: the mediating role of parenting styles on toddlers' DSM-related symptoms. J Aggress Maltreat Trauma 22(2):211-229. doi:10.1080/10926771.2013.743941

Snaith RP (2003) The Hospital Anxiety and Depression Scale. Health Qual Life Outcomes 1:29. doi:10.1186/1477-7525-1-29

Solomon J, George C (1999) The caregiving system in mothers of infants: a comparison of divorcing and married mothers. Attach Hum Dev 1(2):171-190. doi:10.1080/14616739900134221 
Solomon J, George C (2011) The disorganized attachment-caregiving system: dysregulation of adaptive processes at multiple levels. In: Solomon J, George C, Solomon J, George C (eds) Disorganized attachment and caregiving. Guilford Press, New York, pp 3-24

Suchman N, McMahon T, DeCoste C, Castiglioni N, Luthar S (2008) Ego development, psychopathology, and parenting problems in substance-abusing mothers. Am J Orthopsychiatry 78(1):20-28. doi:10.1037/0002-9432.78.1.20

Sullivan MA, Rudnik-Levin F (2001) Attention deficit/hyperactivity disorder and substance abuse. Diagnostic and therapeutic considerations. Ann NY Acad Sci 931:251-270

Tedgård E (2008) Psykoterapeutiskt behandlingsarbete i späd och små barnsfamiljer-. en utvärdering. Evaluation report. Child and Adolecent Psychiatry, Viktoriagården, Malmö

Tronick E, Reck C (2009) Infants of depressed mothers. Harv Rev Psychiatry 17(2):147-156. doi:10.1080/10673220902899714

Velleman R, Templeton L, Reuber D, Klein M, Moesgen D (2008) Domestic abuse experienced by young people living in families with alcohol problems: results from a cross-European study. Child Abuse Rev 17(6):387-409
Weitoft GR, Hjern A, Haglund B, Rosén M (2003) Mortality, severe morbidity, and injury in children living with single parents in Sweden: a population-based study. Lancet 361(9354):289-295. doi:10.1016/ S0140-6736(03)12324-0

Wilens TE, Martelon M, Joshi G, Bateman C, Fried R, Petty C, Biederman J (2011) Does ADHD predict substance-use disorders? A 10-year follow-up study of young adults with ADHD. J Am Acad Child Adolesc Psychiatry 50(6):543-553. doi:10.1016/j.jaac.2011.01.021

Young SE, Friedman NP, Miyake A, Willcutt EG, Corley RP, Haberstick BC, Hewitt JK (2009) Behavioral disinhibition: liability for externalizing spectrum disorders and its genetic and environmental relation to response inhibition across adolescence. J Abnorm Psychol 118(1):117-130. doi:10.1037/ a0014657

Yule AM, Wilens TE, Martelon MK, Simon A, Biederman J (2013) Does exposure to parental substance use disorders increase substance use disorder risk in offspring? A 5-year follow-up study. Am J Addict 22(5):460-465 doi:10.1111/j.1521-0391.2013.12048.x

Zigmond AS, Snaith RP (1983) The hospital anxiety and depression scale. Acta Psychiatr Scand 67(6):361-370

\section{Submit your manuscript to a SpringerOpen ${ }^{\circ}$ journal and benefit from:}

- Convenient online submission

- Rigorous peer review

- Immediate publication on acceptance

- Open access: articles freely available online

- High visibility within the field

- Retaining the copyright to your article 